\title{
Pre-Diabetes Induces Ultrastructural Alterations in the Large Blood Vessel Aorta in Rats
}

\author{
La Prediabetes Induce Alteraciones Ultraestructurales en \\ la Aorta de los Grandes Vasos Sanguíneos en Ratas
}

\begin{abstract}
Abbas O. El Karib ${ }^{1}$; Mohammad Dallak ${ }^{1}$; Mohamed Abd Ellatif ${ }^{2,4}$; Refaat A. Eid ${ }^{3}$; Mohamed A. Haidara ${ }^{1,5}$ \& Bahjat Al-Ani ${ }^{1}$
\end{abstract}
EL KARIB, A. O.; DAllaK, M.; ABD Ellatif, M.; EID, R. A.; HAIDARA, M. A. \& AL-ANI, B. Pre-Diabetes induces ultrastructural alterations in the large blood vessel aorta in rats. Int. J. Morphol., 37(2):647-653, 2019.

SUMMARY: Excessive consumption of carbohydrate and fat increases the risk of cardiovascular disease. We sought to determine the potential ultrastructural alterations in large blood vessels induced by a high fat and fructose diet (HFD) in a rat model of prediabetes. Rats were either fed with HFD (model group) or a standard laboratory chow (control group) for 15 weeks before being sacrificed. The harvested thoracic aorta tissues were examined using transmission electron microscopy (TEM), and blood samples were assayed for biomarkers of pre-diabetes.TEM images showed that HFD induced profound pathological changes to the aortic wall layers, tunica intima and tunica media ultrastructures in the pre-diabetic rats as shown by apoptotic endothelial cells with pyknotic nuclei, damaged basal lamina, deteriorated smooth muscle cells that have irregular plasma membranes, shrunken nucleus with clumped nuclear chromatin, damaged mitochondria and few cytoplasmic lipid droplets and vacuoles. In addition, HFD significantly $(\mathrm{p}<0.05)$ decreased adiponectin and increased biomarkers of lipidemia, glycaemia, inflammation, oxidative stress, vascular injury such as soluble intercellular adhesion molecule-1 (sICAM-1), soluble vascular cell adhesion protein 1 (sVCAM-1), endothelin-1 (ET-1), and coagulation and thrombosis such as Von Willebrand factor (vWF), and plasminogen activator inhibitor-1 (PAI-1), compared to normal levels of these parameters in the control group. Thus, we demonstrated that feeding rats with a HFDisable to develop a pre-diabetic animal model that is useful to study the aortic ultrastructural alterations.

KEY WORDS: Aorta; Ultrastructure; Pre-diabetes; Vascular injury; Rat model.

\section{INTRODUCTION}

Carbohydrate and saturated fats are believed to be the major diet components that promote obesity and insulin resistance (IR) (Kopelman, 2000; Lustig et al., 2012). Abdominal obesity is a criteria of the metabolic syndrome, also called pre-diabetes, which is a cluster of abnormalities characterized by insulin resistance, inflammation, oxidative stress, hypertension and dyslipidaemia which carries increased risk of type 2 diabetes mellitus, cardiovascular disease, non-alcoholic fatty liver disease and cancer (Kopelman; Eckel et al., 2005). IR in adipocytes increases the release of free fatty acids (FFA) from triglyceride stores resulting in hypertriglyceridemia, and dyslipidemia is regarded as a risk factor for the development and progression of hypertension and vascular injury (Elrashidy et al., 2018). In addition, an association between obesity and vascular injury via the upregulation of ICAM, VCAM, vWF, and PAI1 was reported (De Pergola \& Pannacciulli, 2002).

Large blood vessels such as the aorta and pulmonary artery are known targets of pre-diabetes (metabolic syndrome) in humans and animals, which lead to atherosclerosis, hypertension, thrombosis and coagulation, and other vascular injury that involve the up-regulation of inflammation and oxidative stress (Hotamisligil, 2006; Soto et al., 2014). The adiponectin hormone is secreted exclusively by the adipose tissue and reported to be involved

\footnotetext{
${ }^{1}$ Department of Physiology, College of Medicine, King Khalid University, Abha 61421, Saudi Arabia.

${ }^{2}$ Department of Clinical Biochemistry, College of Medicine, King Khalid University, Abha 61421, Saudi Arabia.

${ }^{3}$ Department of Pathology, College of Medicine, King Khalid University, Abha 61421, Saudi Arabia.

${ }^{4}$ Department of Medical Biochemistry, Faculty of Medicine, Mansoura University, Mansoura, Egypt.

${ }^{5}$ Department of Physiology, Kasr al-Aini Faculty of Medicine, Cairo University, Cairo, Egypt.

Funding This work was supported by King Khalid University grant number KKU-Project No. R.G.P.1/27/38.
} 
in the above mentioned process since it acts as an antiinflammatory, anti-oxidant, cytoprotective, and lipid and sugar lowering agent (Yamauchi \& Kadowaki, 2008). Therefore, the aim of the present study was to investigate whether the induction of pre-diabetes upon feeding rats with HFD for 15 weeks was able to cause ultrastructure alterations of a large blood vessel, the aorta, using TEM and blood chemistry.

\section{MATERIAL AND METHOD}

Animals. All experimental procedures were approved by the medical research ethical committee at King Khalid University and according to the Guide for the Care and Use of Laboratory Animals published by the US National Institutes of Health. (NIH publication No. 85-23, revised 1996). Sprague-Dawley rats $(n=12)$ weighing 170 $200 \mathrm{~g}$ were used in this study. All rats were bred and housed in the research centre of King Khalid University, college of medicine (Abha, Saudi Arabia), at a temperature of $23 \pm 1$ ${ }^{\circ} \mathrm{C}$ and a $12 \mathrm{~h}$ light: $12 \mathrm{~h}$ dark cycle. Rats had free access to tap water and fed standard laboratory chow during the acclimatization period.

Experimental design. After a one week adaptation, the rats were randomly divided into two groups ( $n=6$ rats each). Animals in group 1 (Control) were used as the control group and fed with standard laboratory chow for 15 weeks. Animals in group 2 (HFD) were fed a Western-type high-fat diet plus $20 \%$ fructose for 15 weeks (Aragno et al., 2009).

\section{Biochemical measurements}

Blood samples. At the end of experimental period, blood samples were collected by cardiac puncture under anaesthesia (sodium thiopental at $40 \mathrm{mg} / \mathrm{kg}$ body weight) after an overnight fast of $12 \mathrm{~h}$, and animals were then culled. Blood samples were collected without anticoagulant, left for $10 \mathrm{~min}$, then centrifuged for $10 \mathrm{~min}$ at $4000 \mathrm{r} / \mathrm{min}$ to obtain serum, which was stored at $-20{ }^{\circ} \mathrm{C}$ until further biochemical analysis for determination of the glycemic status of these animals, serum lipids, inflammatory biomarkers, and vascular activation biomarkers. Whereas, blood samples that were collected with anticoagulant (sodium citrate) to obtain plasma that was stored at $4^{\circ} \mathrm{C}$, was used for the determination of certain coagulation and prothrombotic parameters.

Determination of serum levels of glucose, insulin, cholesterol, triglyceride, LDL-C, HDL-C, TNF- $\alpha$, IL-6, and hs-CRP. Animals were sacrificed after 15 weeks, and blood levels of glucose and insulin (El Karib et al., 2016) were determined colourimetrically using a Randox reagent kit (Sigma-Aldrich) for glucose and Ultra-Sensitive ELISA Kit (Crystal Chem Inc., Spain)for insulin. Triglycerides (TG) and total cholesterol (TC), low-density lipoprotein cholesterol (LDL-C), and high-density lipoprotein cholesterol (HDL-C) were measured using commercial kits supplied by SPINREACT, Spain, according to the manufacturer's instructions. ELISA kits for determination of serum levels of TNF- $\alpha$, (ELISA kit BIOTANG INC, Cat. No. R6365, MA, USA), Interleukin-6 (IL-6) (ELISA kit BIOTANG INC, Cat. No. RB1829, MA, USA), and high sensitive C-reactive protein (hs-CRP) (ELISA kit, Cat. No. ERC1021-1) from ASSAYPRO, USA, were used as recommended by the manufacturer.

Measurements of adiponectin, soluble ICAM-1 and VCAM-1, ET-1, vWF, and PAI-1. Animals were sacrificed after 15 weeks, and the serum levels of adiponectin, endothelial and leukocyte intercellular adhesion molecule1 (ICAM-1), vascular cell adhesion protein 1 (VCAM-1), endothelin-1 (ET-1), and plasma levels of Von Willebrand factor (vWF), and plasminogen activator inhibitor-1 (PAI1) were determined (Dallak et al., 2018a) using rat ELISA Assay kits purchased from MyBioSource (San Diego, USA) for ICAM-1, VCAM-1, and vWF; ET-1 from R\&D Systems, USA; PAI-1 activity (pg/ ml) was assayed by a commercial kit (Catalog No. CSBE07948r, Cusabio, China).Serum adiponectin was performed using the mouse/ rat adiponectin ELISA kit (B-Bridge International, Inc.), according to the manufacturer's instructions.

Transmission Electron Microscopy (TEM). Small pieces of thoracic aorta tissues were removed and immediately fixed in $2.5 \%$ glutaraldehyde for 24 hours and washed with phosphate buffer (0.1 M, PH 7.4). Post-fixation was made in $1 \%$ osmium tetroxide buffered to $\mathrm{PH} 7.4$ with $0.1 \mathrm{M}$ phosphate buffer at $4{ }^{\circ} \mathrm{C}$ for $1-2 \mathrm{~h}$. The samples washed in phosphate buffer to remove excess fixative, dehydrated through ascending grades of ethanol followed by clearing in propylene oxide. The specimens were embedded in Araldite 502, to form gelatin capsules. Polymerization was obtained by placing the capsules at $60{ }^{\circ} \mathrm{C}$. Semi-thin sections $(\sim 1 \mathrm{~mm}$ thick) were stained with toluidine blue for orientation and observation. Ultra-thin sections (100 $\mathrm{nm}$ ) were prepared using ultra-microtome and picked up on uncoated copper grids. Following double staining with uranylacetate and lead citrate, three to five random micrographs for each section were examined and photographed using a JEM-1011-JEOL transmission electron microscope, Japan, at $80 \mathrm{Kv}$ (Dallak et al., 2018b). The effect of HFD was determined by assessing the integrity of aortic endothelium and smooth muscle cells in 50 fields scored as $\%$ positivity. 
Statistical analysis. The data was expressed as the mean \pm standard deviation (SD). Data was processed and analyzed using the SPSS version 10.0 (SPSS, Inc., Chicago, Ill., USA). One-way ANOVA was done followed by Tukey's post hoc test. Pearson correlation statistical analysis was done for detection of a probable significance between two different parameters. Results were considered significant if $p \leq 0.05$.

\section{RESULTS}

Induction of glycaemia and lipidemia in a rat model of prediabetes by HFD. We first sought to characterize the animal model of pre-diabetes induced by HFD. High blood levels of glucose (Fig. 1A), insulin (Fig. 1B), TC (Fig. 1C), TG (Fig. 1D), LDL-C (Fig. 1E), and low blood levels of HDL$\mathrm{C}$ (Fig. 1F) measured in the model group of rats fed on HFD for 15 weeks, which were compared with the control group confirmed the development of glycaemia and lipidemia in our animal model of pre-diabetes. In addition, HFD caused about $55 \%$ increase in weight gain compared to about $30 \%$ gain in the control group (data not shown).
Induction of inflammation and oxidative stress in a rat model of pre-diabetes by HFD.We further characterized our model of pre-diabetes and assessed the level of inflammatory and oxidative stress biomarkers that are known to be increased in metabolic syndrome / pre-diabetes. Feeding rats for 15 weeks on HFD caused a significant $(\mathrm{p}<0.05)$ increase in the blood levels of TNF- $\alpha$ (Fig. 2A), IL-6 (Fig. 2B), hs-CRP (Fig. 2C), and tissue level of MDA (Fig. 2D).

Induction of vascular activation and coagulation and thrombosis, and inhibition of adiponectin in a rat model of pre-diabetes by HFD. Up-regulation of Inflammation and down-regulation of adiponectin are well known to cause endothelial activation and vascular injury. To determine whether biomarkers of vascular injury are modulated in our pre-diabetes rat model, we measured the blood levels of adiponectin, soluble ICAM-1 and VCAM-1, ET-1, vWF, and PAI-1 in the animal groups. HFD caused a significant $(p<0.05)$ decrease in adiponectin levels (Fig. 3A), and augmentation of sICAM-1 (Fig. 3B), sVCAM-1 (Fig. 3C), ET-1 (Fig. 3D), vWF (Fig. 3E), and PAI-1 (Fig. 3F).
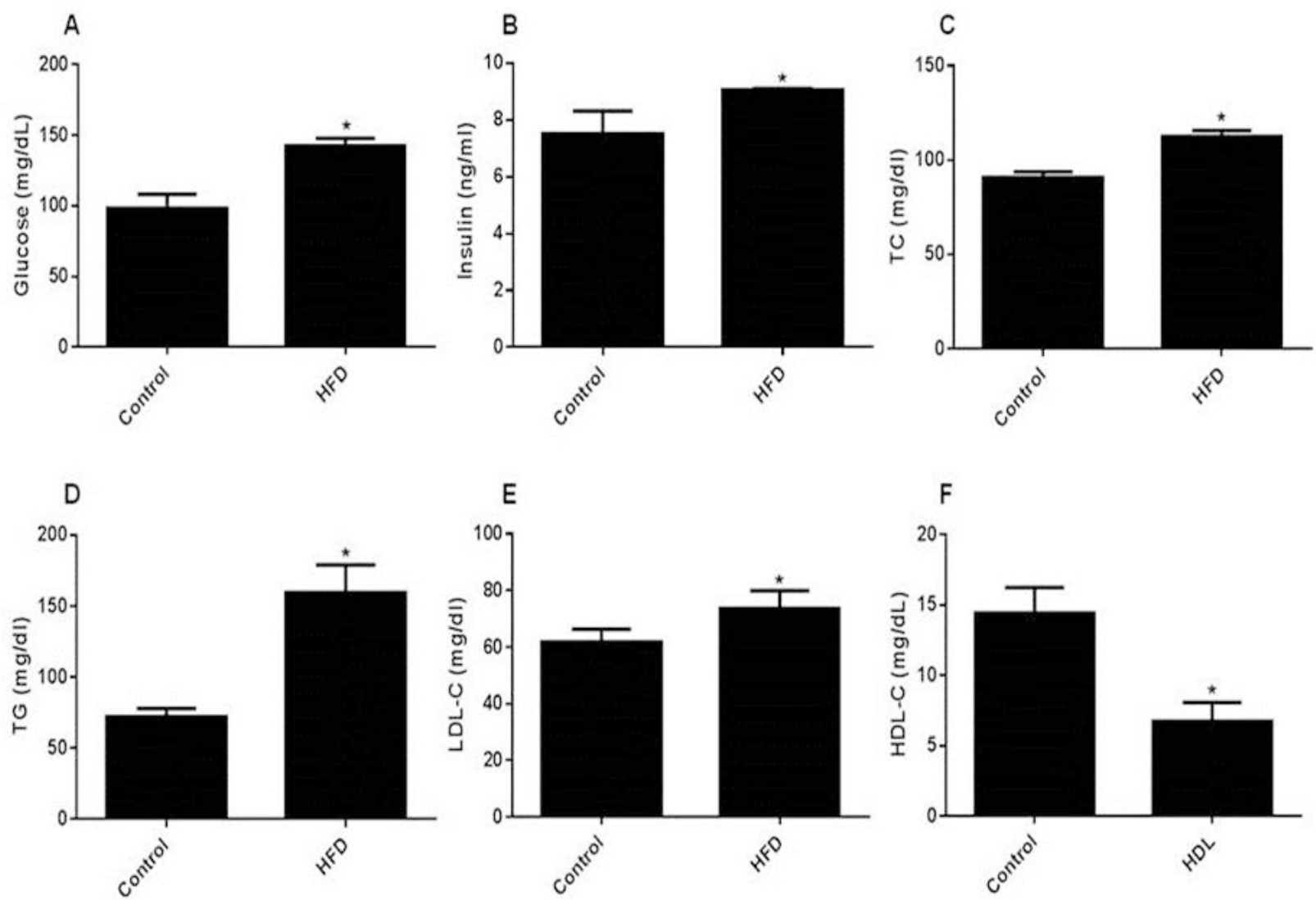

Fig. 1. Induction of glycaemia and lipidemia in rats fed on HFD. Blood levels of glucose (A), insulin (B), TC (C), TG (D), LDL$\mathrm{C}(\mathrm{E})$, and HDL-C (F), were measured in 2 groups of rats; Control and HFD groups after 15 weeks. Results represent the mean $( \pm \mathrm{SD}) ; \mathrm{n}=6$ for each group. Experiments were performed in triplicate. $* \mathrm{p}<0.05$ versus control. 

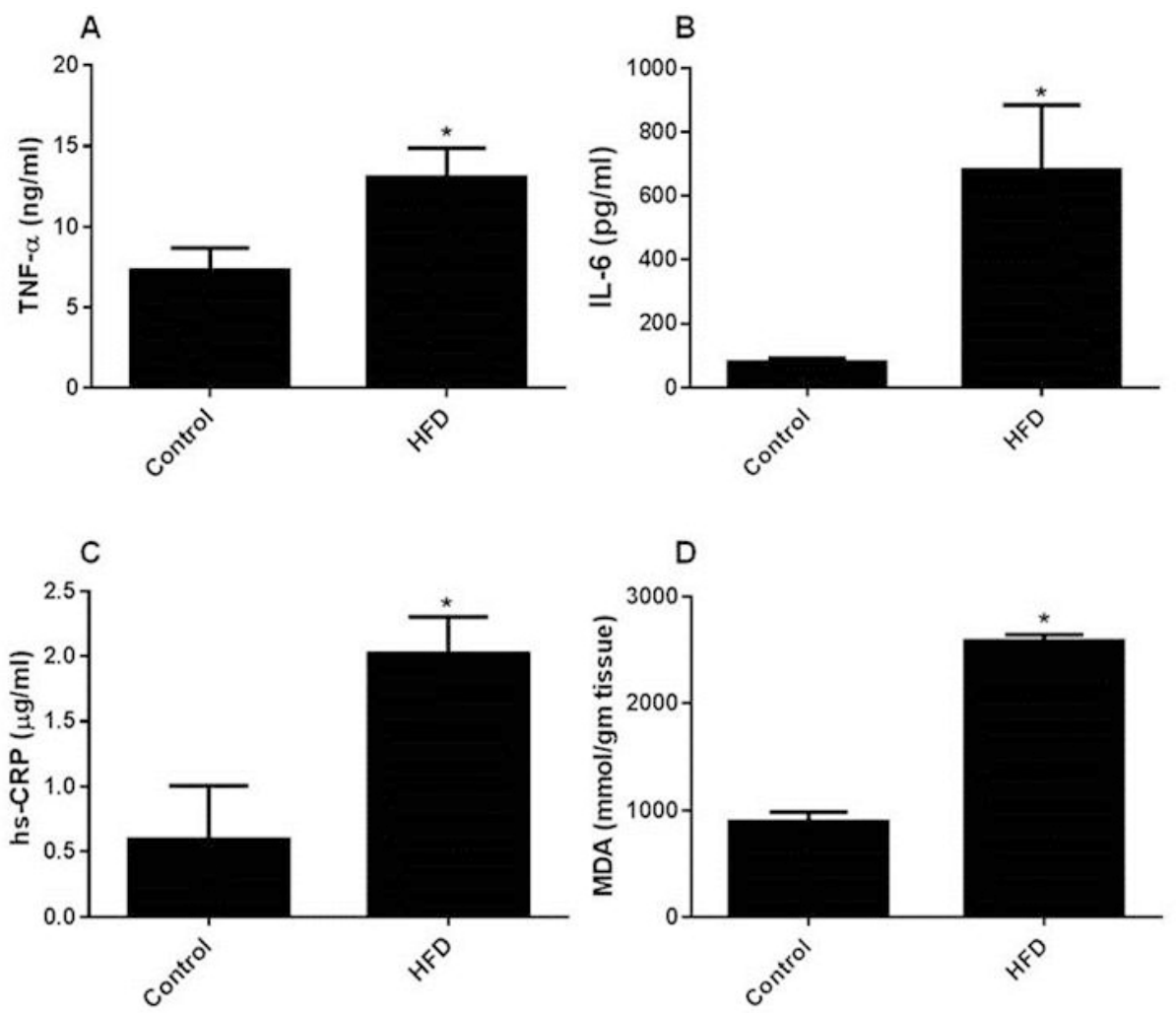

Fig. 2. Induction of inflammation and oxidative stress biomarkers in rats fed on HFD. Blood levels of TNF- $\alpha$ (A), IL-6 (B), hs-CRP (C), and tissue levels of MDA(D) were measured in 2 groups of rats; Control and HFD groups after 15 weeks. Results represent the mean $( \pm \mathrm{SD}) ; \mathrm{n}=6$ for each group. Experiments were performed in triplicate. $* \mathrm{p}<0.05$ versus control.
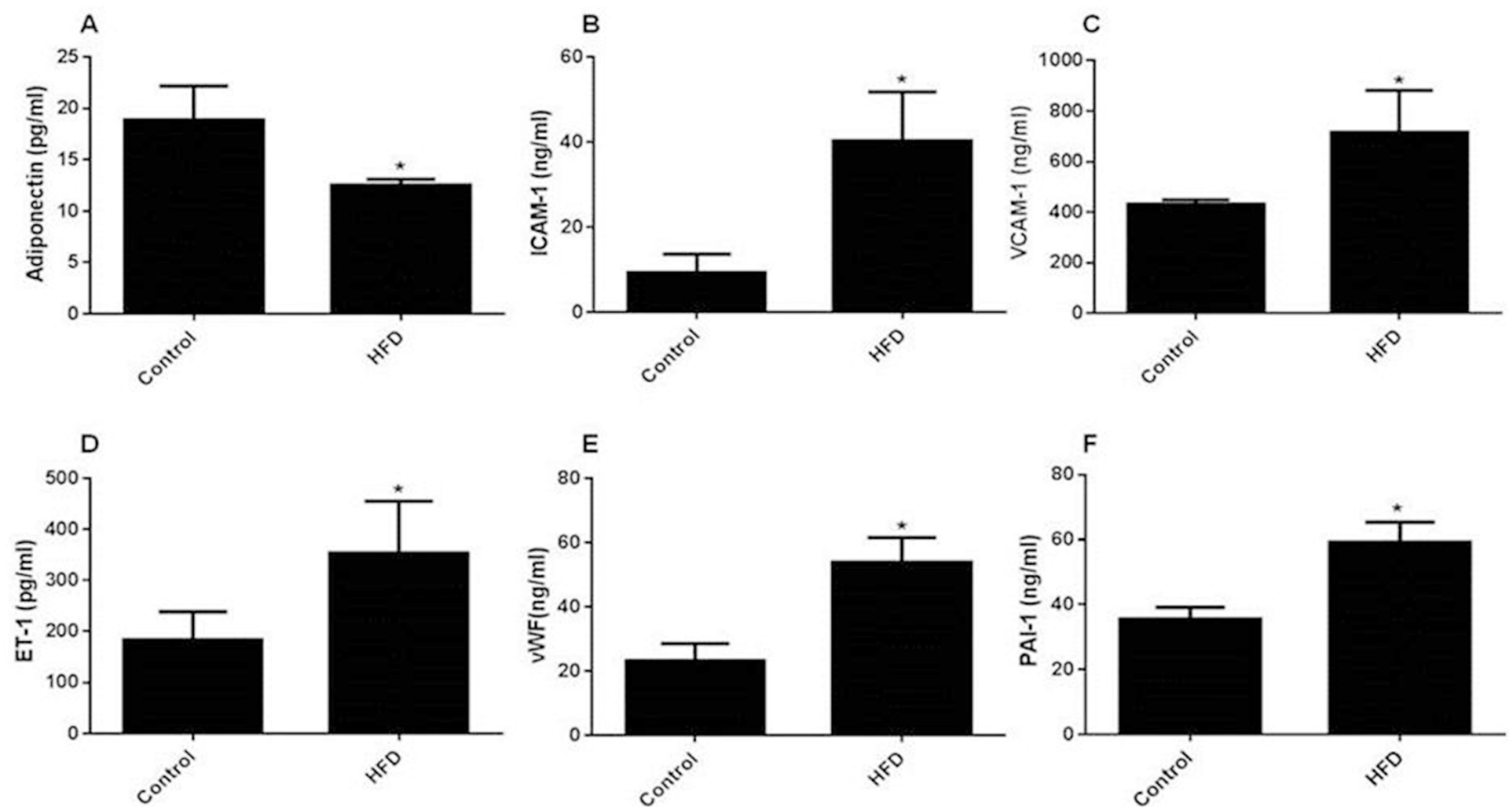

Fig. 3. Inhibition of adiponectin and induction of endothelial activation, coagulation and thrombosis biomarkers in rats fed on HFD. Blood levels of adiponectin (A), sICAM-1 (B), sVCAM-1 (C), ET-1 (D), vWF (E), and PAI-1 (F), were measured in 2 groups of rats; Control and HFD groups after 15 weeks. Results represent the mean $( \pm \mathrm{SD}) ; \mathrm{n}=6$ for each group. Experiments were performed in triplicate. $* \mathrm{p}<0.05$ versus control. 
HFD induces aorta ultrastructural alterations in a rat model of pre-diabetes. Using TEM technique, we assessed whether HFD in our model can induce vascular injury to the large blood vessels. We therefore, investigated aortic tissue architectures in the model group after 15 weeks and compared it with the control group. TEM images obtained from the aortic wall layers, tunica intima (Fig. 4B) and tunica media (Fig. 4D) in the pre-diabetic rats showed substantial ultrastructural alterations as shown byapoptotic endothelial
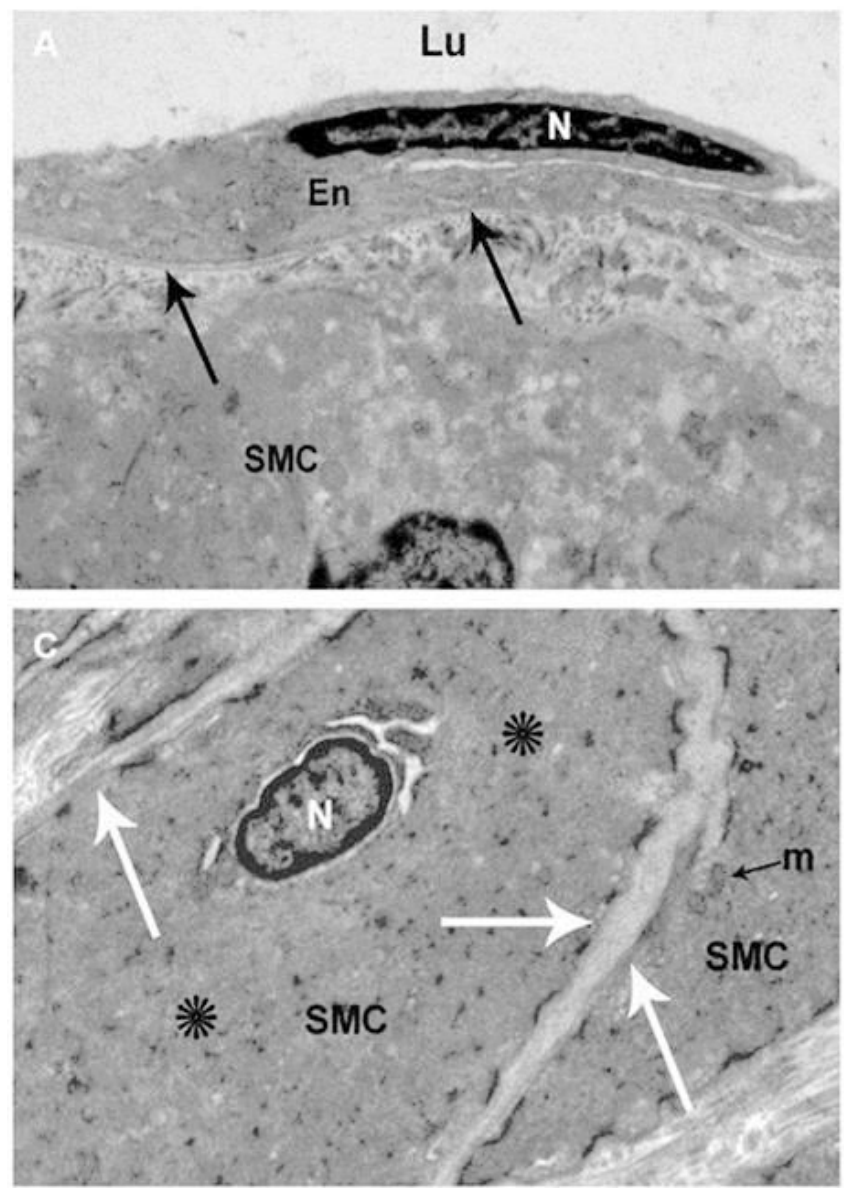

cells with pyknotic nuclei, damaged basal lamina, deteriorated smooth muscle cells that have irregular plasma membranes, irregular shrunken nucleus with clumped nuclear chromatin, damaged mitochondria and few cytoplasmic lipid droplets and vacuoles. Whereas, the control group showed intact endothelial (Fig. 4A) and smooth muscle cells (Fig. 4C) compartments. Approximately $65 \%$ of the scanned aortic endothelial cells and $45 \%$ of the vascular SMC in the HFD group had poor morphology.
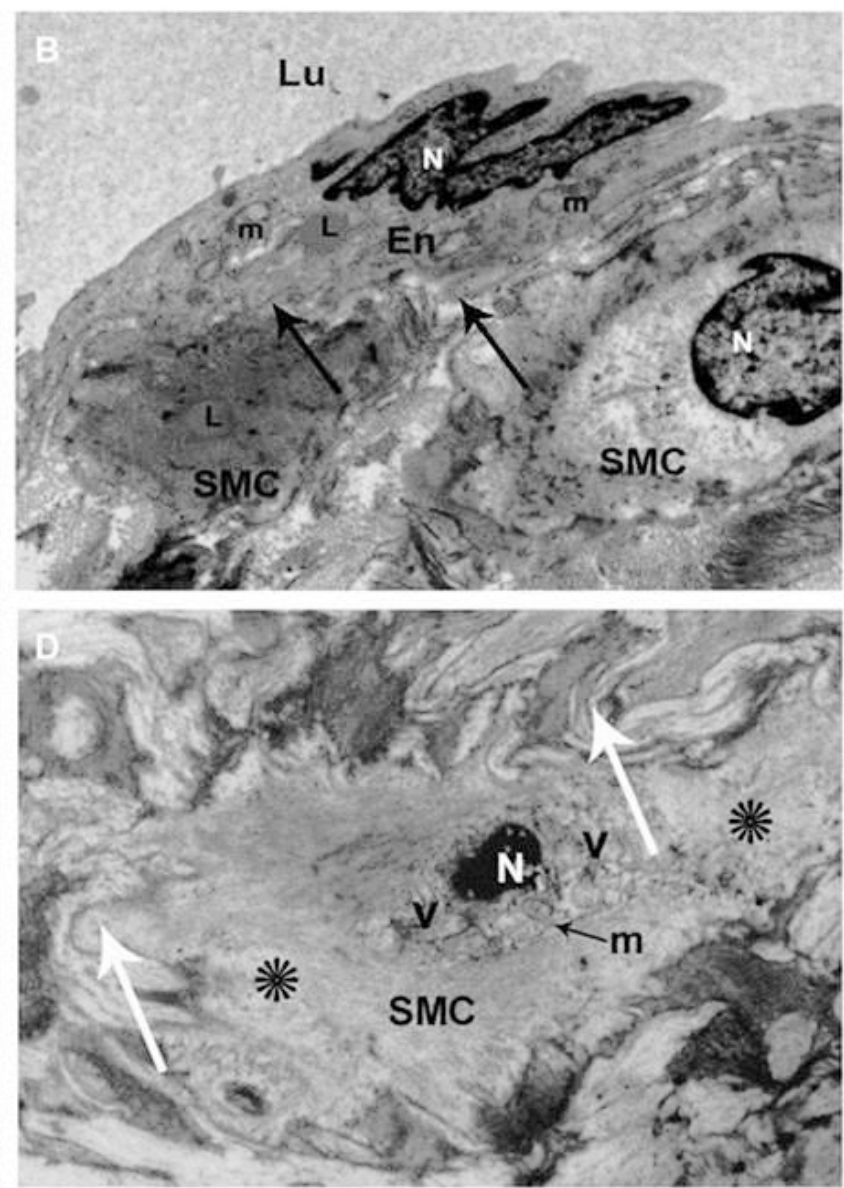

Fig. 4. Induction of aortopathy in rats fed on HFD.TEM images of the aortic wall layer tunica intima (A and B, 5000x) and tunica media (C and D, 8000x) obtained at week 15. Representative TEM image of the tunica intima obtained from the control animal group (A) compared to the HFD group (B) is depicted. Part of the tunica media is shown in both (A and B).(C and D). Representative TEM image of the tunica media obtained from the control animal group (C) compared to the HFD group (D). Note that the black arrows in (A and B) point to the basal lamina, and white arrows in $(\mathrm{C}$ and $\mathrm{D})$ point to the plasma membranes, whereas asterisks in $(\mathrm{C}$ and $\mathrm{D})$ point to the lattice-like network of actin and myosin filaments. Abbreviations: N, nucleus; En, endothelial cell; Lu, lumen; L, lipid droplets; m, mitochondria; v, vacuoles; SMC, smooth muscle cells.

\section{DISCUSSION}

The main objective of this study was to investigate whether a rat model of pre-diabetes can be beneficial in assessing alterations to large blood vessel ultrastructures using TEM analysis. Therefore, we induced metabolic syndrome in one group of rats fed on a HFD for 15 weeks before being sacrificed. A comparison was also made between the pathological and biochemical changes which occurred in these animals. The main findings of our study 
were that pre-diabetes induced alterations to the aortic ultrastructure, which were accompanied by the induction of biomarkers of inflammation, oxidative stress, vascular injury, coagulation and thrombosis, and inhibition of adiponectin. The above conclusions are supported by the data indicating that HFD induced substantial pathological changes to the aortic wall layers, tunica intima and tunica media ultrastructures in the pre-diabetic rats (Fig. 4). In addition, HFD caused glycaemia and dyslipidemia (Fig. 1), marked decrease in adiponectin (Fig. 3A), an increase in inflammation and oxidative stress biomarkers (TNF- $\alpha$, IL6, hs-CRP, and MDA) (Fig. 2), vascular injury biomarkers (sICAM-1, sCAM-1, and ET-1), and coagulation and thrombosis (vWF and PAI-1) (Fig. 3).

Inflammation and oxidative stress induced by dyslipidemia and IR represent a common mechanism underlying the vascular injury observed in obesity and diabetes (Shoelson et al., 2006). In addition, the link between adiponectin inhibition and vascular injury is documented (Woodward et al., 2017). Therefore, our data that demonstrate a decrease in adiponectin level and elevation of inflammatory and oxidative stress biomarkers and aortopathy are in agreement with these studies. Similarly, our data that demonstrate a link between atherosclerosis, thrombosis, coagulation, and vascular activation and aortopathy are also in agreement with the previously published reports that showed a clear link between these parameters and aortic injury (King \& Ajjan, 2017).

Our protocol of feeding rats with a high fat and fructose diet for 15 weeks have led to IR, obesity, and cardiovascular disease (CVD), is in agreement with several rodent models for type 2 diabetes mellitus such as Zucker Diabetic Fatty (ZDF) rats from Charles River that develop obesity, insulin resistance and CVD at a younger age, which are available and successfully used to mimic CVD in humans (Siwy et al., 2012).

Collectively, this study demonstrates that feeding rats with a HFD diet for 15 weeks produced a pre-diabetic animal model that caused aortic ultrastructural alterations accompanied by dyslipidemia and IR, reduction in adiponectin, and augmentation of inflammatory, oxidative stress, vascular activation, and thrombosis and coagulation biomarkers.

\section{ACKNOWLEDGEMENTS}

The authors appreciate the help of Marwa Al-Ani from Sutton Coldfield, Birmingham, UK for proofreading the manuscript.
EL KARIB, A. O.; DALLAK, M.; ABD ELLATIF, M.; EID, R. A.; HAIDARA, M. A. \& AL-ANI, B. La prediabetes induce alteraciones ultraestructurales en la aorta de los grandes vasos sanguíneos en ratas. Int. J. Morphol., 37(2):647-653, 2019.

RESUMEN: El consumo excesivo de carbohidratos y grasas aumenta el riesgo de enfermedades cardiovasculares. Intentamos determinar las posibles alteraciones ultraestructurales en los grandes vasos sanguíneos, inducidas por una dieta alta en grasas y fructosa (HFD) en un modelo de rata de prediabetes. Las ratas se alimentaron con HFD (grupo modelo) o una comida de laboratorio estándar (grupo de control) durante 15 semanas antes de ser sacrificadas. Los tejidos de la aorta torácica recolectados se examinaron mediante microscopía electrónica de transmisión (TEM) y las muestras de sangre se analizaron para detectar biomarcadores de prediabetes. Las imágenes TEM mostraron que HFD indujo cambios patológicos profundos en las capas de la pared aórtica, túnica íntima y túnica media en la ratas pre-diabéticas como lo muestran las células endoteliales apoptóticas con núcleos picnóticos, lámina basal dañada, células musculares lisas deterioradas que tienen membranas plasmáticas irregulares, núcleo encogido con cromatina nuclear aglomerada, mitocondrias dañadas y pocas gotitas lipídicas citoplásmicas y vacuolas. Además, HFD presentó disminución significativa de adiponectina ( $\mathrm{p}<0,05)$, y aumento de biomarcadores de lipidemia, glucemia, inflamación, estrés oxidativo, lesión vascular como la molécula de adhesión intercelular soluble 1 (sICAM-1), proteína de adhesión de células vasculares soluble 1 (sVCAM-1), endotelina 1 (ET-1), y la coagulación y la trombosis, como el factor de Von Willebrand (vWF), y el inhibidor del activador del plasminógeno-1 (PAI -1), en comparación con los niveles normales de estos parámetros en el grupo de control. Por tanto, la alimentación de ratas con HFD es capaz de desarrollar un modelo animal prediabético que es útil para estudiar las alteraciones ultraestructurales aórticas.

PALABRAS CLAVE: Ultraestructura; Aorta; Pre-diabetes; Lesión vascular; Modelo de rata.

\section{REFERENCES}

Aragno, M.; Tomasinelli, C. E.; Vercellinatto, I.; Catalano, M. G.; Collino, M.; Fantozzi, R.; Danni, O. \& Boccuzzi, G. SREBP-1c in nonalcoholic fatty liver disease induced by Western-type high-fat diet plus fructose in rats. Free Radic. Biol. Med., 47(7):1067-74, 2009.

Dallak, M. A.; Bin-Jaliah, I.; Albawardi, A.; Haidara, M. A.; Sakr, H. F.; Eid, R. A.; Hassan, W. N. \& Al-Ani, B. Swim exercise training ameliorates hepatocyte ultrastructural alterations in rats fed on a high fat and sugar diet. Ultrastruct. Pathol., 42(2):155-61, 2018b.

Dallak, M.; Bin-Jaliah, I.; Sakr, H. F.; Al-Ani, B. \& Haidara, M. A. Swim exercise inhibits hemostatic abnormalities in a rat model of obesity and insulin resistance. Arch. Physiol. Biochem., 13:1-6, $2018 \mathrm{a}$.

De Pergola, G. \& Pannacciulli, N. Coagulation and fibrinolysis abnormalities in obesity. J. Endocrinol. Invest., 25(10):899-904, 2002.

Eckel, R. H.; Grundy, S. M. \& Zimmet, P. Z. The metabolic syndrome. Lancet, 365(9468):1415-28, 2005.

El Karib, A. O.; Al-Ani, B.; Al-Hashem, F.; Dallak, M.; Bin-Jaliah, I.; ElGamal, B.; Bashir, S. O.; Eid, R. A. \& Haidara, M. A. Insulin and vanadium protect against osteoarthritis development secondary to dia- 
betes mellitus in rats. Arch. Physiol. Biochem., 122(3):148-54, 2016.

Elrashidy, R. A.; Zhang, J. \& Liu, G. Long-term consumption of Western diet contributes to endothelial dysfunction and aortic remodeling in rats: Implication of Rho-kinase signaling. Clin. Exp. Hypertens., 41(2):174-80, 2019.

Hotamisligil, G. S. Inflammation and metabolic disorders. Nature, 444(7121):860-7, 2006.

King, R. J. \& Ajjan, R. A. Vascular risk in obesity: Facts, misconceptions and the unknown. Diab. Vasc. Dis. Res., 14(1):2-13, 2017.

Kopelman, P. G. Obesity as a medical problem. Nature, 404(6778):63543, 2000.

Lustig, R. H.; Schmidt, L. A. \& Brindis, C. D. Public health: The toxic truth about sugar. Nature, 482(7383):27-9, 2012.

Shoelson, S. E.; Lee, J. \& Goldfine, A. B. Inflammation and insulin resistance. J. Clin. Invest., 116(7):1793-801, 2006.

Siwy, J.; Zoja, C.; Klein, J.; Benigni, A.; Mullen, W.; Mayer, B.; Mischak, H.; Jankowski, J.; Stevens, R.; Vlahou, A.; Kossida, S.; Perco, P. \& Bahlmann, F. H. Evaluation of the Zucker diabetic fatty (ZDF) rat as a model for human disease based on urinary peptidomic profiles. PLoS One, 7(12):e51334, 2012.

Soto, M. E.; Soria-Castro, E.; Lans, V. G.; Ontiveros, E. M.; Hernández Mejía, I.; Martínez Hernández, H. J.; Barragán García, R.; Herrera, V. \& Pérez-Torres, I. Analysis of oxidative stress enzymes and structural and functional proteins on human aortic tissue from different aortopathies. Oxid. Med. Cell. Longev., 2014:760694, 2014.

Woodward, L.; Akoumianakis, I. \& Antoniades, C. Unravelling the adiponectin paradox: novel roles of adiponectin in the regulation of cardiovascular disease. Br. J. Pharmacol., 174(22):4007-20, 2017.

Yamauchi, T. \& Kadowaki, T. Physiological and pathophysiological roles of adiponectin and adiponectin receptors in the integrated regulation of metabolic and cardiovascular diseases. Int. J. Obes. (Lond.), 32 Suppl. 7:S13-8, 2008.

\section{Corresponding author: \\ Professor Bahjat Al-Ani \\ Department of Physiology \\ College of Medicine \\ King Khalid University \\ Abha 61421}

SAUDI ARABIA

Email: bahjat_alani@yahoo.com

Received: 03-09-2018

Accepted: 08-01-2019 